\title{
Analysis of Rectangular Notch Antenna for Dual-Band Operation
}

\author{
Rajesh Kumar Vishwakarma ${ }^{1}$, Sanjay Tiwari ${ }^{2}$ \\ School of Studies in Electronics, Pt. Ravishankar Shukla University, Raipur, Chhattisgarh (C.G) \\ E-mail:rkv_786@yahoo.com,drsanjaytiwari@gmail.com \\ Received August 27, 2009; revised September 14, 2009; accepted September 20, 2009
}

\begin{abstract}
In this paper a design of single layer rectangular notch microstrip antenna for dual-band is proposed and experimentally investigated. This antenna is excited by microstrip line. Direct microstrip coupling with proper matching transformer has been used. Design is made for optimized notch dimension for two resonant frequencies. These resonance frequencies change with the variation in length and width of the notch. The input impedance and VSWR have been measured with the help of Network analyzer. It is found that the input impedance and VSWR depends variation in length and width of the notch microstrip antenna.
\end{abstract}

Keywords: Microstrip Antenna, Notch Antenna, Dual-Band Antenna, Matching Transformer

\section{Introduction}

Microstrip antennas are receiving much attention at present because they offer many practical advantages such as small size, lightweight, low cost and a low profile ease of fabrication and integration with RF devices [1]. In the recent years, radar, satellite communication wireless networks such as global positioning system (GPS), synthetic aperture radar (SAR), often require dual frequency patch antenna to avoid the use of two different antennas. An ideal dual-frequency antenna should have similar performance in both operating modes. One of the principal disadvantages of such antenna is narrow bandwidth. Recently several papers [2-4] have been published treating notch microstrip antenna to achieve dual band characteristics. The major limitation of microstrip antenna lies in its limited bandwidth. Several methods have been reported in the literature [5-7] to improve the bandwidth of the microstrip antenna such as thicker substrate use of parasitic elements, proximity coupling of the feed line, and stacked microstrip antennas. Recently Palit [8] et al has reported a microstrip antenna by properly cutting a notch inside the radiating element. This properly fields enough BW for dual band frequency and broadband operation. In this case dual resonance is obtained by a dipole loaded notch antenna [9], notch loaded patch antenna [10], and notch triangular microstrip antenna [11] at the radiating edge of patch. The idea is extended by designing variation of length and width of the notch antenna. In the present work, and the effect of notch length and width on the resonance frequencies have been carried out.

\section{Feeding Network}

The microstrip line method is easy to fabricate simple to model and match by controlling the inset cut position in the patch in the (Figure 1). Matching transformers transform the input resistance of patch to $50 \mathrm{ohm}$ coaxial cable. The ratio $W / h$ of the microstrip line used for feeding network can patch to found as to follows. The effective dielectric constant change with the ratio of strip width $W$ to thickness $h$ as [12]

$$
\varepsilon_{\text {eff }}=\left(\frac{\varepsilon_{r}+1}{2}\right)+\left(\frac{\varepsilon_{r}-1}{2}\right) \cdot\left(1+\frac{10 \cdot h}{w}\right)^{-0.5}
$$

when then define

$$
Z_{o}=Z \sqrt{\varepsilon_{\text {eff }}}
$$

where $Z$ is the strip impedance. The formula for $Z_{0}=$ for $W / h \leq 1 \quad$ can be given as

$$
\begin{gathered}
Z_{0}=60 \ln \left(\frac{8 H}{w}+\frac{w}{4 h}\right) \text { for } \frac{W}{h} \leq 1 \\
Z_{0}=\frac{120 \pi}{\frac{W}{h}+2.42-0.44 \frac{h}{W}\left(1-\frac{h}{W}\right)^{6}} \text { for } \frac{W}{h} \succ 1
\end{gathered}
$$

We can find the impedance when $W / h$ is known but most design problem required the otherwise i.e. give $Z$ 


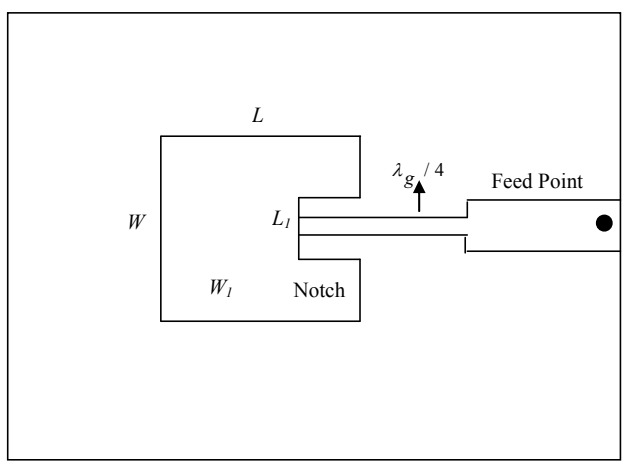

Figure 1. The notch rectangular microstrip antenna.

fin $W / h$, So Equations (1) and (3) or (4) in an interactive process are used to find $W / h$ when $W / h=1$, We first find $Z_{0}$ of $W / h=1$ and then $\varepsilon_{\text {eff }}$ and impedance are calculated as.

$$
\begin{gathered}
\varepsilon_{\text {eff }}=\left(\frac{\varepsilon_{r}+1}{2}\right)+\left(\frac{\varepsilon_{r}-1}{2}\right) \frac{W}{h}=1 \\
Z_{o}=Z \sqrt{\varepsilon_{\text {eff }}}
\end{gathered}
$$

and

$$
Z_{o}=Z \sqrt{\varepsilon_{e f f}(1)}
$$

where

$$
Z_{0}=126.6\left(\frac{W}{h}=1\right)
$$

If $Z_{0}$ is greater than $Z_{0}(1)$ then $W / h$ using is less or equal 1

Case 1 When $\frac{W}{h} \leq 1$ then

$$
\frac{W}{h}=2\left(\exp \left(\frac{Z_{0}}{60}\right)-\sqrt{\left[\exp \left(\frac{Z_{0}}{60}\right)\right]^{2}-8}\right)
$$

starting with $\varepsilon_{\text {eff }}(1)$ we solve for $\frac{W}{h}$ using this value. We find $\varepsilon_{\text {eff }}\left(\frac{W}{h}\right)$ from equation. Then it is substituted back in 13 to find a new value of $\frac{W}{h}$

Case 2 when $\frac{W}{h}>1$ we use Newton's method of the finding function zero to form an integration equation.

$$
\begin{aligned}
\text { Let } X & =\left(\frac{W}{h}\right) \\
\left(\frac{W}{h}\right)_{\text {new }} & =X\left[\frac{1-X^{2}+X\left(2.42+\left(1-\frac{1}{X}\right)^{6}-\frac{120 \pi}{Z_{0}}\right)}{X^{2}+0.44+6\left(1-\frac{1}{X}\right)^{5}}-0.44\right]
\end{aligned}
$$

using the new $\frac{W}{h}$ we find $\varepsilon_{\text {eff }} \frac{W}{h}$ and a new value of $Z_{0}$. A good starting value for the iteration is found from

$$
\frac{W}{h}=\frac{120}{Z_{0}}-198
$$

Iteration method has been done from Equations 1 to 9 and converges in a few cycles.

\section{Measurement Techniques}

The network analyzer is used to perform the measurement. Glass epoxy substrate with thickness of $h=1.59$ $\mathrm{mm}$ and approximate dielectric constant $\varepsilon_{r}=4.5$ was used. Several patches were fabricated with the variation of notch length and width. The variation of lower and upper resonance frequencies with notch length and width are shown in the Figures 6(a) and 6(b). The variation of upper and lower resonance frequencies ratio $\left(f_{2} / f_{1}\right)$ with notch length and width are shown in the Figures 7(a) and 7(b). The resulting data are shown in Tables 1 to 2 .

\section{Design Procedure and Design Parameters}

The actual dimension of the antenna designed is magnified two times in order to achieve the desired accuracy in the final design. The antenna shape of enlarged dimension is taken times in rubylith film. This enlarge shape is photo reduced using a high precision camera to produce a high-resolution negative, which is later used for exposing the photo resist. The laminate is cleaned to insure proper adhesion of the photo resist and necessary resolution in the photo development process. The photo resist is now applied to both sides of the laminate using a laminator. After wards, the laminate is allowed to stand to normalize to room temperature prior to exposure and development. The photographic negative is now held in a very close contact with the cover sheet of the applied

Table 1. Variation of resonance frequencies with notch length for a given width $=10 \mathrm{~mm}$.

\begin{tabular}{cccc}
\hline $\begin{array}{c}\text { Length } \\
(\mathrm{mm})\end{array}$ & $\begin{array}{c}\text { Frequency } \\
\left(f_{1}\right) \mathrm{GHz}\end{array}$ & $\begin{array}{c}\text { Frequency } \\
\left(f_{2}\right) \mathrm{GHz}\end{array}$ & $\begin{array}{l}\text { Frequencies } \\
\text { ratio } \\
\left(f_{2} / f_{1}\right) \mathrm{GHz}\end{array}$ \\
\hline 2 & 2.998 & 4.525 & 1.527 \\
3 & 2.993 & 4.606 & 1.613 \\
4 & 3.01 & 4.523 & 1.513 \\
5 & 3.01 & 4.619 & 1.609 \\
\hline
\end{tabular}

Table 2. Variation of resonance frequencies with notch width for a given length $=\mathbf{2} \mathbf{m m}$.

\begin{tabular}{cccc}
\hline $\begin{array}{c}\text { Width } \\
(\mathrm{mm})\end{array}$ & $\begin{array}{c}\text { Frequency } \\
\left(f_{1}\right) \mathrm{GHz}\end{array}$ & $\begin{array}{c}\text { Frequency } \\
\left(f_{2}\right) \mathrm{GHz}\end{array}$ & $\begin{array}{c}\text { Frequencies } \\
\text { ratio } \\
\left(f_{2} / f_{1}\right) \mathrm{GHz}\end{array}$ \\
\hline 6 & 2.955 & 4.497 & 1.542 \\
7 & 2.930 & 4.522 & 1.592 \\
8 & 2.953 & 4.534 & 1.581 \\
9 & 2.962 & 4.535 & 1.572 \\
\hline
\end{tabular}


photo resist, to assure the fine line resolution required with exposure to proper wave length light, polymerization of the exposed photo resist occurred, making it insoluble in developer solution. The backside of the antenna is completely exposed without a mask, since the copper foil is retained to act as a ground plane. The protective cover sheet of the photo resist is removed and the antenna is now developed in developer, which remove the soluble photo resist material.

Then the antenna is etched. Visual inspection is used to assure proper etching. Then excess photo resist is removed using a stripping solution. For stack antenna, the passive antenna are made with single side PCB same as done for active antenna.

The various design parameters of the antenna are as follows:

Substrate material used Glass Epoxy

Thickness of the dielectric substrate $h=1.59 \mathrm{~mm}$

Relative permittivity of the substrate $\varepsilon_{\mathrm{r}}=4.5$

Design frequency $f=3.0 \mathrm{GHz}$

Thickness of the patch $t=0.0018 \mathrm{~cm}$ and designed values were calculated using the standard equations, which are

The width of the rectangular patch $W=30.15 \mathrm{~mm}$

The length of the rectangular patch $L=23.04 \mathrm{~mm}$

The length of the notch $L_{l}=1.0 \mathrm{~mm}$ to $5 \mathrm{~mm}$ at fixed width $=10 \mathrm{~mm}$

The width of the notch $W_{1}=6 \mathrm{~mm}$ to $10 \mathrm{~mm}$ at fixedlength $=2 \mathrm{~mm}$

\section{Discussion of Results}

1) The variation of input impedance with frequency for different notch length for a given width is shown in Figures 2(a) to 2(d). It is observed that notch microstrip antenna shows dual resonance in which lower and upper resonance frequencies increases with increasing notch length from $2 \mathrm{~mm}$ to $5 \mathrm{~mm}$.

2) The variation of input impedance with frequency for different notch width for a given length is shown in Figures 3(a) to 3(d). It is observed that notch microstrip

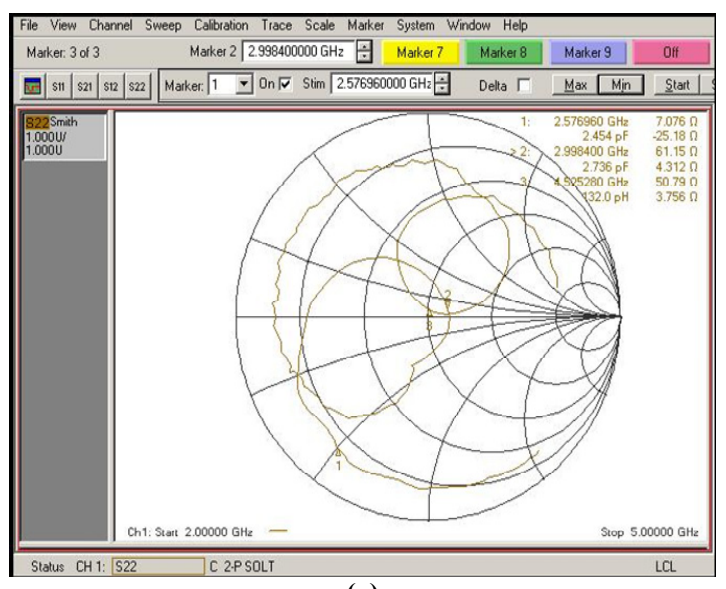

(a)

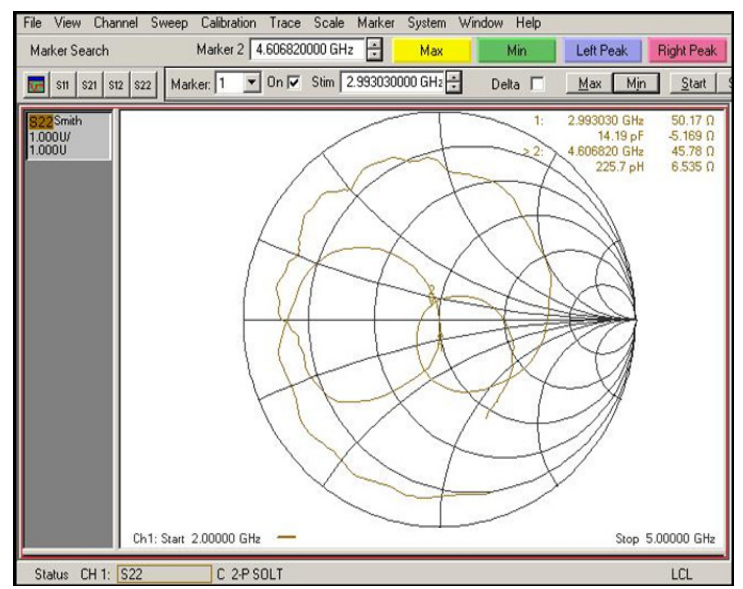

(b)

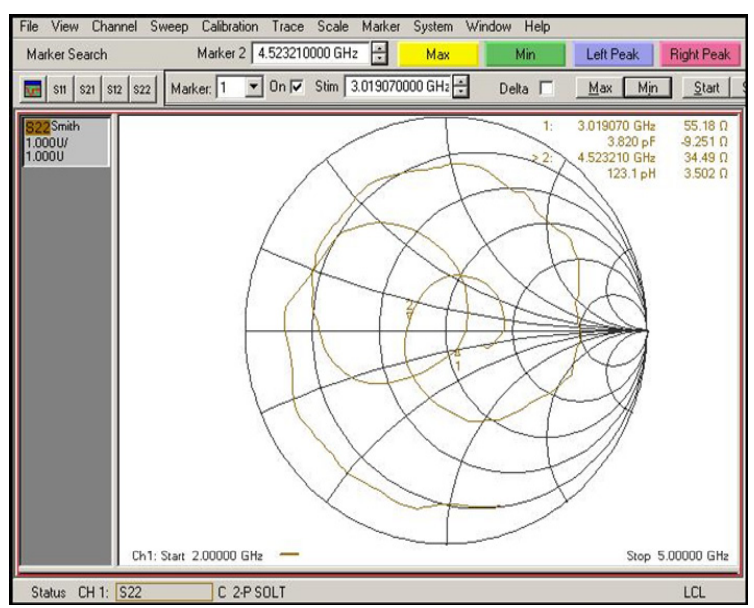

(c)

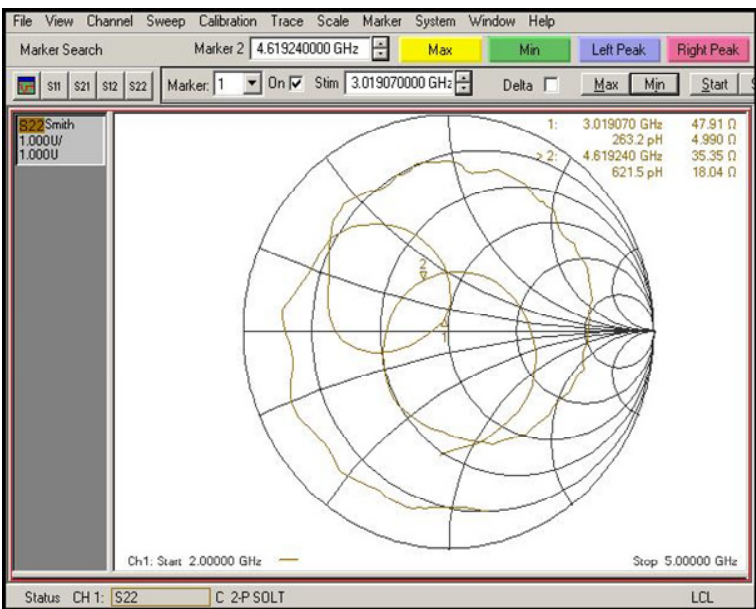

(d)

Figure 2. (a) Variations of input impedance with frequency for notch length $=2 \mathrm{~mm}$ at width $=10 \mathrm{~mm}$; (b) Variations of input impedance with frequency for notch length $=3 \mathrm{~mm}$ at width $=10 \mathrm{~mm}$; (c) Variations of input impedance with frequency for notch length $=4 \mathrm{~mm}$ at width $=10 \mathrm{~mm}$; (d) Variations of input impedance with frequency for notch length $=5 \mathrm{~mm}$ at width $=10 \mathrm{~mm}$. 
antenna shows dual resonance in which lower resonance frequency increases with increasing notch width from $6 \mathrm{~mm}$ to $9 \mathrm{~mm}$,where as upper resonance is all most constant with varying notch width.

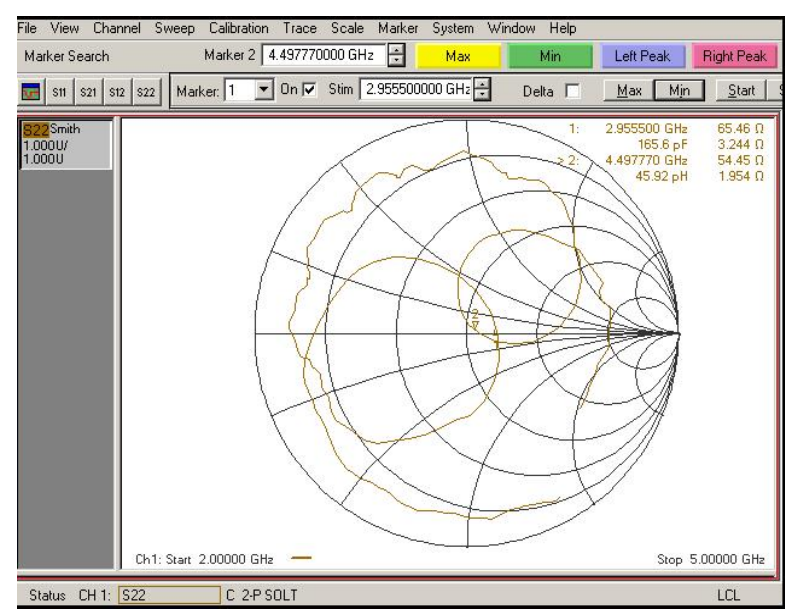

(a)

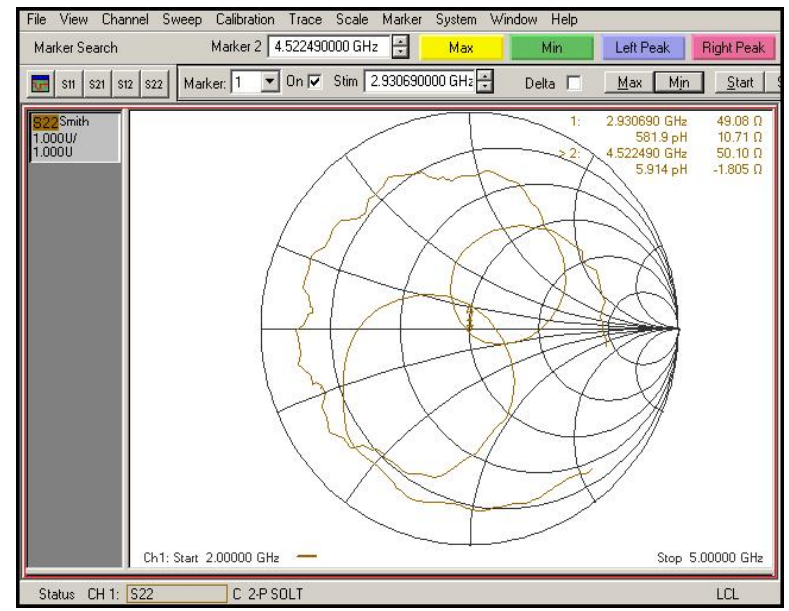

(b)

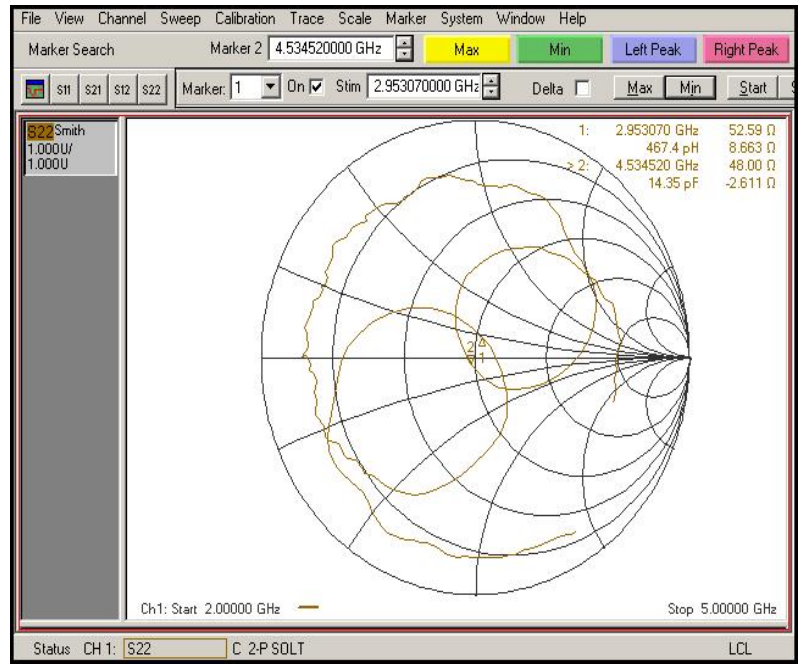

(c)

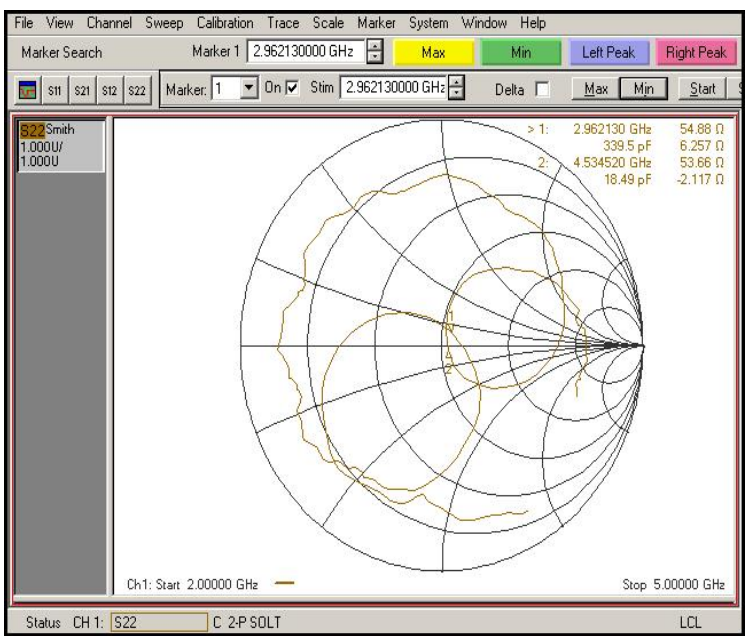

(d)

Figure 3. (a) Variations of input impedance with frequency for notch width $=6 \mathrm{~mm}$ at length $=2 \mathrm{~mm}$; (b) Variations of input impedance with frequency for notch width $=7 \mathrm{~mm}$ at length $=2 \mathrm{~mm}$; (c) Variations of input impedance with frequency for notch width $=8 \mathrm{~mm}$ at length $=2 \mathrm{~mm}$; (d) Variations of input impedance with frequency for notch width $=$ $9 \mathrm{~mm}$ at length $=\mathbf{2} \mathrm{mm}$.

3) The variation of VSWR with frequency for different notch length for a given width are shown in Figures 4(a) to 4(d) It is observed that the value of VSWR corresponding to lower resonance frequency is decreased from 1.27 to 1.11 with increasing notch length where as

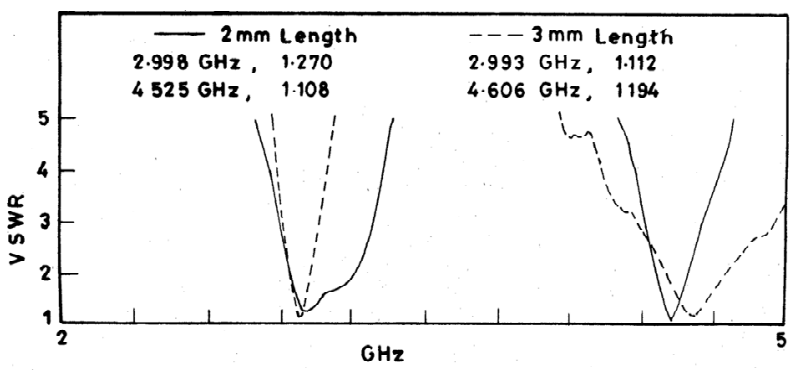

(a)

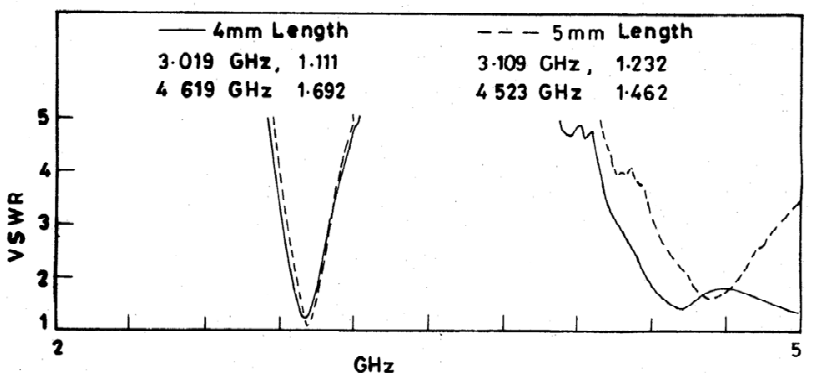

(b)

Figure 4. (a) Variations of VSWR with frequency for notch length $=2 \mathrm{~mm}$ and $3 \mathrm{~mm}$ notch at width $=10 \mathrm{~mm}$; (b) Variations of VSWR with frequency for notch length $=4$ $\mathrm{mm}$ and $5 \mathrm{~mm}$ at notch width $=10 \mathrm{~mm}$. 
corresponding to the upper resonance frequency the value of VSWR is increased from 1.10 to 1.69 .

4) The variation of VSWR with frequency for different notch width for given length are shown in Figures 5(a) to 5(d). It is observed that the value of VSWR corresponding to lower resonance frequency is decreased from 1.12 to 1.08 .

5) The variation of resonance frequencies with notch dimensions is shown in the Figures 6(a) to 6(b). It is observed that both resonance frequencies are increased with notch dimensions.

6) The variation of resonance frequency ratio $f_{2} / f_{1}$ with notch dimensions is shown in the Figures 7(a) to 7(b). It is observed that both resonance frequencies are increases with notch dimensions.

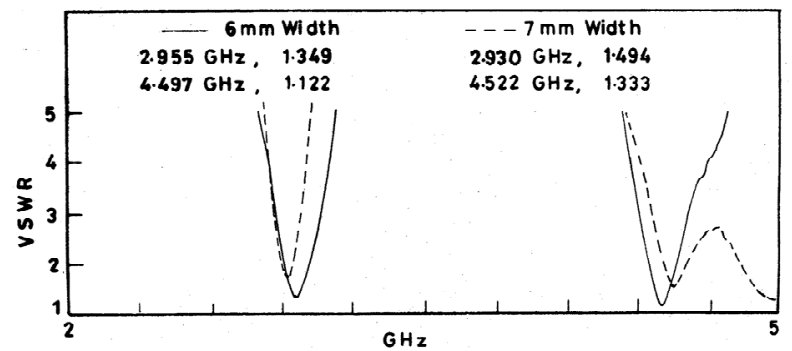

(a)

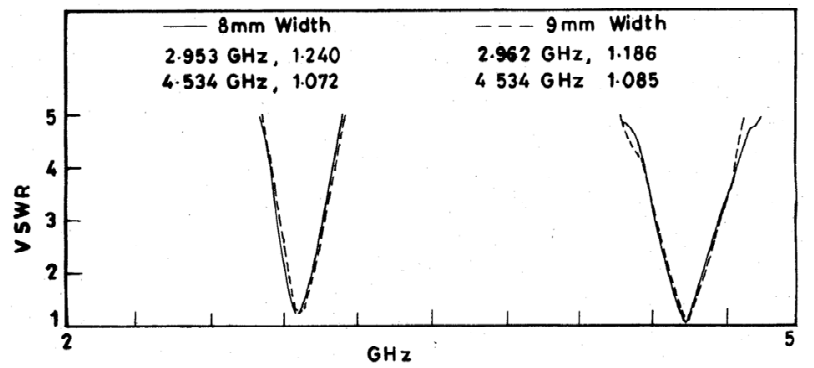

(b)

Figure 5. (a) Variations of VSWR with frequency for notch width $=6 \mathrm{~mm}$ and $7 \mathrm{~mm}$ at notch length $=2 \mathrm{~mm}$; (b) Variations of VSWR with frequency for notch width $=8 \mathrm{~mm}$ and $9 \mathrm{~mm}$ at notch length $=\mathbf{2} \mathrm{mm}$.

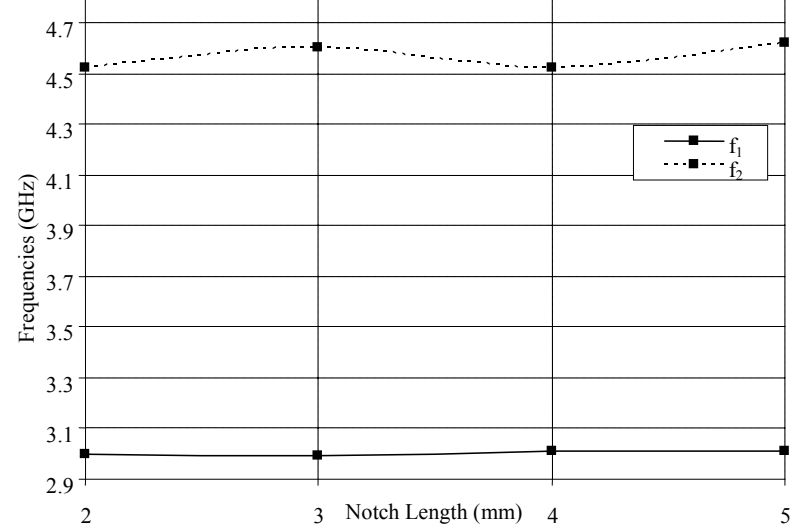

(a)

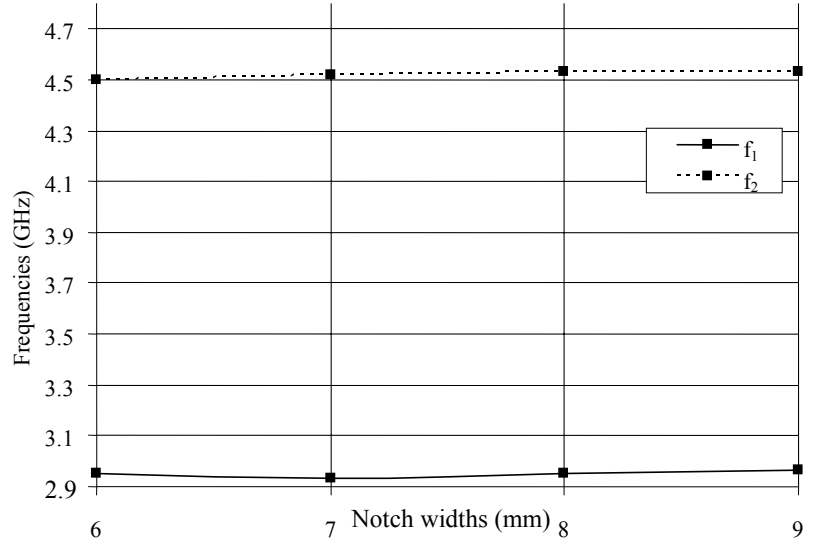

(b)

Figure 6. (a) Variations of resonance frequencies with notch lengths for a given width; (b) Variations of resonance frequencies with notch width for a given length.

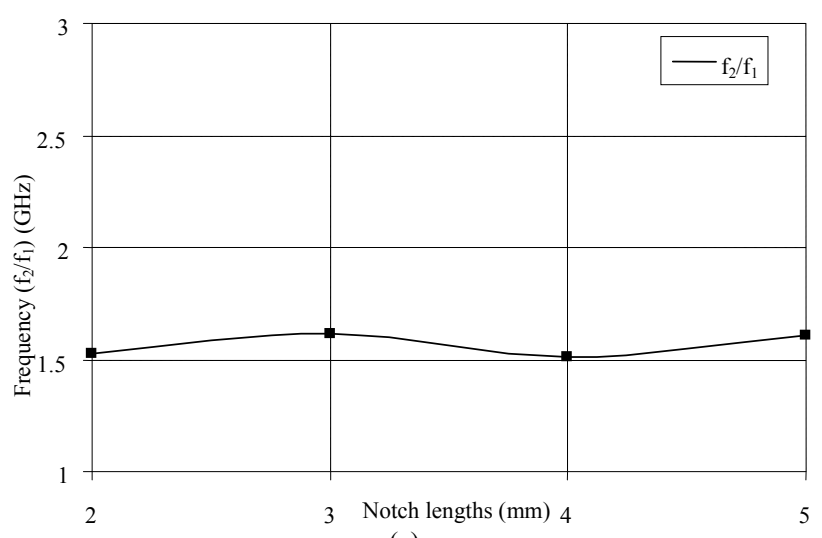

(a)

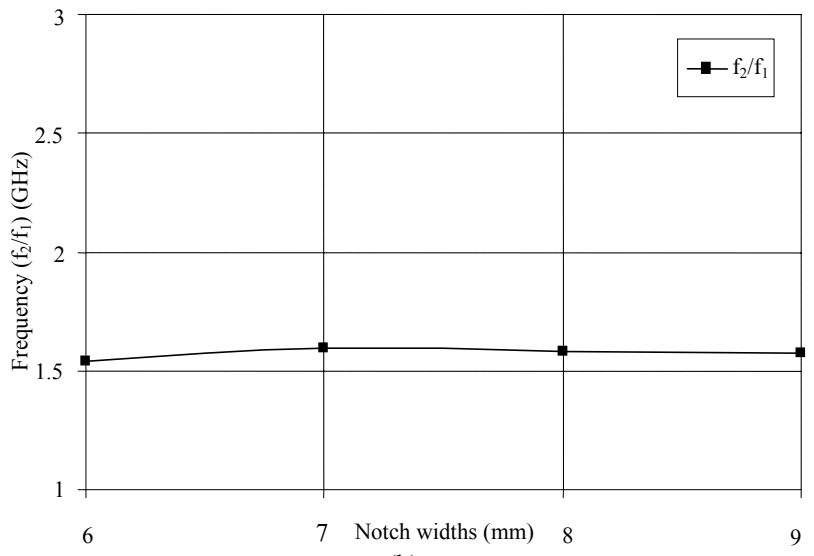

(b)

Figure 7. (a) Variation of frequency ratios $\left(f_{2} / f_{1}\right)$ with notch length for a given width; (b) Variation of frequency ratios (f2/f1) with notch width for a given length.

\section{Acknowledgment}

The authors would like to thank Professor Arun Kumar and Shri R. K. Malaviya of the Space Application Centre, Indian Space Research Organization Ahmedabad, for 
providing the measurement facilities.

\section{References}

[1] I. J. Bahl and P. Bharta, Microstrip Antenna, Artech House, Massachusetts, USA, 1980.

[2] S. K. Polit and A. Hamad, "Dual-band notch microstrip antenna for mobile communications," Asia Pacific Microwave Conference Proceeding New Delhi, Vol. 2, pp. 299-302, pp. 17-20, December 1996.

[3] H. Nakano and K. Vichien, "Dual-frequency square patch antenna with rectangular notch," Electronics Letters, Vol. 25, No. 16, pp. 1067-1068, August 1989.

[4] L. I. Basilio, A. K. Jeffery, T. Williams, and A. S. Long, "The dependence of the input impedance on feed position of probe and microstrip line fed patch antenna," IEEE Transactions on Antennas Propagation, Vol. AP-49, pp. 45-47 January 2001.

[5] E. Chang, S. A. Zong, and W. F. Richards, "An experimental investigation of electrically thick rectangular microstrip antenna," IEEE Transactions on Antennas Propagation, Vol. AP-34, pp. 767-772, 1986.
[6] D. M. Pozar and B. Kaufman, "Increasing the band width of a microstrip antenna by proximity coupling," Electronics Letters, Vol. 23, No. 8, pp. 368-369, April 1987.

[7] H. F. Pues and A. V. V. De Capelle, "An impedance matching technique increasing the band width of microstrip antenna," IEEE Transactions on Antenna and Propagation, Vol. AP-37, No. 11, pp. 1345-1354, November 1989.

[8] S. K. Palit "Broad band microstrip antenna design, Chinese Journal of radio science, August 1995.

[9] C. L. Li, C. F. Wen, and Y. K. Ling, "Dual-band dipole-loaded notch antenna," The 23rd International Technical Conference on Circuits/Systems, Computers and Communications (ITC-CSCC 2008), pp. No-1797-1800.

[10] Shivnarayan and B. R. Vishvakarma, "Analysis of notch loaded patch for dual-band operation," Indian journal of Radio and Space Physics, Vol. 35, pp. 435-442, 2006.

[11] J. Y. Hui, and Z. S. shi, "Notch triangular microstrip antenna for dual-frequency operation," Journal of Shanghai University, pp. No-375-378, 2003.

[12] M. V. Schneider, "Microstrip lines for microwave integrated circuits," Bell System Technology Journal, Vol.48, pp. 1421-1444, May-June 1969. 